\title{
Criminologie
}

\section{Notes sur un type de criminel dans la littérature populaire}

\section{Jacqueline De Plaen}

Volume 14, numéro 1, 1981

Criminalité et réalités sociales : Québec, Canada, États-Unis, Japon

URI : https://id.erudit.org/iderudit/017134ar

DOI : https://doi.org/10.7202/017134ar

Aller au sommaire du numéro

Éditeur(s)

Les Presses de l'Université de Montréal

ISSN

0316-0041 (imprimé)

1492-1367 (numérique)

Découvrir la revue

Citer ce document

De Plaen, J. (1981). Notes sur un type de criminel dans la littérature populaire.

Criminologie, 14(1), 111-117. https://doi.org/10.7202/017134ar d'utilisation que vous pouvez consulter en ligne.

https://apropos.erudit.org/fr/usagers/politique-dutilisation/ 


\section{NOTES SUR UN TYPE DE CRIMINEL DANS LA LITTERATURE POPULAIRE}

Jacqueline De Plaen

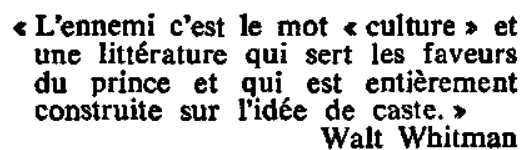

Dès ses origines, la littérature a fourni à la culture populaire de nombreux portraits de criminels. Depuis les pécheurs de la Bible jusqu'aux bandits des plus récentes séries télévisées, une multitude de caractères ont vu le jour, témoignant à la fois de la variété, de l'importance et de la pérennité du délinquant sous toutes ses formes.

Si l'on met de côté les portraits complexes conçus par les grands dramaturges et romanciers dont l'intention est moins de dépeindre le délinquant, que de décrire les conflits qui prennent naissance dans \& la face noire de l'âme humaine 》, on retrouve une foule de caractères fictifs dont l'existence se justifie exclusivement par le fait qu'ils transgressent les normes. De multiples études pourraient être entreprises autour de l'intérêt que le peuple a, de tous les temps, voué au criminel. Il serait intéressant en effet d'examiner les types de délits à travers les diverses approches littéraires, les transformations qu'ils ont subies avec le temps, leur insertion dans les grands mythes, leur évolution avec les sociétés et les diverses perspectives qu'en donne la littérature. Sans aller si loin, nous nous contenterons de jeter un regard c criminologique, sur la tradition littéraire occidentale d'où il semble s'établir spontanément des filiations entre des caractères par ailleurs distincts.

Au-delà des époques et des frontières, et même par-delà la nature des méfaits commis, les déviants se regroupent naturellement autour de la réaction populaire qu'ils suscitent plutôt que par une parenté véritable. N'existent-ils pas, comme c'est le propre de tout être imaginaire, que par et pour ce qu'on en dit ? La culture populaire, en ce sens, demeure plus révélatrice parce que plus proche du vécu social, étant moins psychologique, moins 
individualiste. Un exemple frappant de ce type de famille nous est fourni par ceux qu'on appellerait les « coquins sympathiques \$. Issus d'une littérature d'abord orale, ils font souche, ont leur heure de gloire et meurent à la fin du xIX siècle. Peut-on dire qu'il subsiste encore aujourd'hui des héros populaires qui peuvent se réclamer de cette famille?

\section{Le coquin sympathique}

Le personnage ainsi nommé accomplit vraiment des actes réprouvés par tous et pourtant, il bénéficie auprès de son auditoire d'une tolérance surprenante. Il est vrai qu'il s'agit d'un héros comique et qui se fait l'avocat de la sagesse ordinaire. La loi de la comédie n'est-elle pas de présenter des types empruntés à la vie ? Pourtant la malhonnêteté, la violence, la fausseté qui constituent la trame des 27 récits du Roman de Renart n'appartiennent pas en propre à la morale du XII ${ }^{e}$ siècle pas plus qu'à celle d'Ésope, au $\mathrm{VI}^{\circ}$ siècle avant Jésus-Christ. Ainsi Renart, avec ses nombreux ancêtres et descendants, qui esquive toutes les peines au tribunal de Noble, sort-il également indemne et plutôt grandi de ses aventures devant un public complice, séduit par la finesse des ruses déployées. Il en va de même de Till Eulenspiegel et de ses émules à l'étranger au XIV siècle. Citons encore le personnage de Tit-Jean héros du folklore français et québécois qui, à travers ses nombreux patronymes, n'en demeure pas moins le coquin, voleur, joueur et toujours gagnant. Renart, Eulenspiegel, Scanarelle, le Marquis de Carabas et Tit-Jean ont en commun une basse extraction et le désir de réussir. Ils poursuivent pour leur propre compte, qui un rang social supérieur (en épousant la princesse), qui une vie matérielle plus confortable (en escroquant les mieux nantis). Voler les moutons du roi, duper son maitre ou jouer sa place au paradis n'a jamais figuré au code moral d'aucune époque ni d'aucun pays comme actes vertueux ni, à tout prendre, comme actions permises. Pourtant, la morale populaire a toléré sinon approuvé ce type de coquin en qui le paysan se reconnaissait. Les ruses visant à déjouer l'immobilité des classes sociales et à réaliser les aspirations communes s'accommodaient bien d'entorses à la morale, puisque sans elles, le fils du meunier ne pouvait aspirer à autre chose qu'au destin misérable de meunier. On note que la tolérance quant aux moyens est limitée et conditionnée au succès. Ainsi les grands tabous comme le recours 
à l'homicide, seront respectés. De même, le voleur surpris et capturé aura toujours tort. N'est-il pas aussi rassurant de constater que les victimes occupent toujours un échelon supérieur à leurs agresseurs dans la hiérarchie sociale ? A cet égard, les variantes des contes populaires sont révélatrices : les sociétés coloniales faute de roi et de courtisans devront inventer de nouvelles cibles plus concrètes et plus proches de l'imaginaire collectif. Ainsi, le héros québécois du folklore ne se mesurera plus à des mortels qui sont ses égaux. Dans un conte très répandu, c'est aux saints du paradis qu'il s'en prendra. D'abord refusé au ciel, pour avoir trompé la mort elle-même, Tit-Jean gagne progressivement la première place à la droite de Dieu le Père en jouant son siège aux cartes.

L'apogée littéraire du scélérat récompensé s'incarnera dans les valets de Molière. La fourberie, le chantage et souvent les coups réussissent à extorquer quelques écus et ne sont jamais punis. Ce qui motivera en partie la réprobation janséniste qui a plané longtemps sur le genre comique tout entier. Pourtant, ces satires, nous l'aurons compris, n'étaient qu'une saine catharsis, tout entière destinée à tempérer les injustices sociales, en les sublimant par le rire. *Or la religion », selon Daniel Bell, * impose toujours des normes morales à la culture. Elle indique des limites et assujettit les impulsions esthétiques à une conduite morale. A partir du moment où la culture aborda le démoniaque, apparut l'idée d'une autonomie de l'esthétique, l'idée que l'expérience, en soi, était la valeur suprême : il faut tout explorer, tout permettre (au moins en imagination), y compris le désir charnel, le meurtre et autres thèmes qui dominent le surréel moderniste > (p. 167).

Mais nous n'en sommes pas encore là et au XIX siècle, l'affrontement des classes sociales ouvre à l'initiative personnelle et à l'esprit inventif, des perspectives jusqu'alors ignorées. Point n'est besoin pour réussir, de le faire aux dépends d'un autre. La faveur populaire a d'autres héros de type «aventurier 》. La science et le travail permettent sinon l'ascension sociale, du moins des perspectives de vie intéressantes (Jules Verne) où le crime n'a pas nécessairement de place. Les frontières géographiques et sociales se sont élargies et partant les frontières morales n'offrent plus les mêmes obstacles aux réussites matérielles. Le «coquin sympathique », n'ayant plus de raison d'être, s'éteint de lui-même. 
Cette disparition, dans l'univers de la fiction du xIx siècle, coïncide avec ce que Foucault (1975) nomme la moralisation des classes pauvres ». « Dresser la barrière qui devrait séparer les délinquants de toutes les couches populaires dont ils étaient issus et avec lesquelles ils demeuraient liés, était une tâche difficile, surtout sans doute dans les milieux urbains. On s'y est employé longtemps et avec obstination... On a mis en œuvre des procédés plus particuliers pour entretenir l'hostilité des milieux populaires contre les délinquants $\gg$ (p. 291). Le visage de la victime, de ponctuel et précis qu'il était, est devenu tellement anonyme et vague que les griefs sont disparus, retirant au lecteur toute velléité de complicité.

Le roman criminel de la littérature populaire du siècle dernier marque la rupture de l'identification. \& Il a surtout pour fonction », ajoute Foucault (1975), « de montrer que le délinquant appartient à un monde entièrement autre, sans relation avec l'existence quotidienne et familière. Cette étrangeté, ce fut d'abbord celle des bas-fonds (Les Mystères de Paris, Rocambole), puis celle de la folie (surtout dans la seconde moitié du siècle) enfin celle du crime doré, de la délinquance de « haut vol $\gg$ (Arsène Lupin). Les faits divers joints à la littérature policière ont produit depuis plus d'un siècle une masse démesurée de « récits de crimes » dans lesquels surtout la délinquance apparaît à la fois comme très proche et tout à fait étrangère, perpétuellement menaçante pour la vie quotidienne, mais extrêmement lointaine par son origine, ses mobiles, le milieu où elle se déploie quotidienne et exotique. Par l'importance qu'on lui prête et le faste discursif dont on l'accompagne, on trace autour d'elle une ligne qui, en l'exaltant, la met à part \$ (p. 292).

\section{L'éclatement au personnage}

Un fait nous semble particulièrement significatif de la nouvelle focalisation qu'a prise le récit populaire : de roman criminel, il est devenu roman policier. Le déplacement du héros maintenant agent des forces de l'ordre, serviteur du système conserve à la fiction populaire son caractère sécurisant essentiel. Puisqu'il est devenu impossible de lutter victorieusement contre un ennemi collectif et sans visage, les protagonistes passent à la solde de l'Etat. La majeure partie de la littérature du crime ne conserve plus aucun caractère commun avec les récits anciens. 
Le policier ou le détective (Conan Doyle, Agatha Christie) traquent des criminels inexcusables, demeurant, pour leur part, irréprochables vis-à-vis la loi. Certes, ils ont hérité de la ruse et parfois de l'espièglerie des «coquins sympathiques », mais leur position de poursuivants leur confère un statut plus intellectuel et plus lointain, moins susceptible de susciter l'identification populaire. Le récit classique d'ailleurs porte sur l'enquête criminelle et rarement sur le crime lui-même. Mais ce type de roman semble ne pouvoir \& s'intéresser simultanément au crime et au criminel. Ou bien le criminel s'efface devant son crime (problème), ou bien le crime s'efface devant le criminel (cas psychologique) > (Narcejac, T., 1967).

Une autre catégorie de contrevenants modernes s'apparente à Robin-des-Bois. Ceux-là se distinguent par les mobiles altruistes de leurs actes et jouent, à l'intérieur d'une société imparfaite, les redresseurs de torts : ce sont des faux criminels.

Mais depuis les 20 dernières années, la télévision et le livre ont largement contribué à véhiculer en Amérique, l'image d'un nouveau héros. Celui-ci, tantôt au service des compagnies privées, tantôt au service de l'État lui-même, est plus qu'un simple rejeton humain de la haute technologie. Il marque l'existence d'une nouvelle symbiose entre l'individu et la société. Bigsby l'analyse ainsi, lappliquant à la production télévisée F.B.I. : - In the world created by such television programmes the individual may justifiably fret at petty restrictions, may even exercise his initiative in such a way as to circumvent unnecessary red-tape and arrive at intuitive or deductive perceptions more quickly than slow-moving bureaucracy for which he works, but there is never any doubt as to the rightness of that institution or the desirability of working within its protective framework. The individual tolerates the organization, the corporation tolerates its employee $>$ (p. 5).

L'incarnation la plus populaire de ce héros est sans contredit \& l'agent secret \. Peut-être est-il le seul qui puisse revendiquer des racines lointaines dans la littérature populaire du crime. $\grave{A}$ cause du fait qu'il travaille contre un salaire, comme d'ailleurs la grande majorité des citoyens, l'agent secret partage avec eux le but personnel et légitime de gagner sa vie. Il agit pour le compte d'une puissance en tout point semblable à celle 
qu'il combat et dans laquelle il ne pourra trouver refuge en cas d'échec. L'objectif qui lui est imposé n'est pas discutable, on lui laisse seul le choix des moyens. Par ailleurs, les récits sont entièrement axés sur les actes criminels eux-mêmes perpétrés à l'insu des forces de l'ordre et dépourvus de tout mobile humanitaire. L'espion rejoint le mythe du duel en s'opposant au malfaiteur répugnant, il incarne le manichéisme propre à l'imagination populaire. Une tolérance nouvelle pour le meurtre constitue la principale différence entre l'espion-agent secret et le coquin de la Renaissance.

A cause de l'interpénétration des genres, on retrouve l'agent secret dans de multiples contextes dont la science fiction. La technologie de l'instrumentation (on ira jusqu'à l'introduire à l'intérieur de l'organisme même de l'agent), les nouveaux champs d'action (interplanétaires) de même que la variété des missions prescrites proviennent des distorsions imprimées à l'espace et au temps du monde réel mais ils ne servent pas que de maquillage à la similitude des intrigues et des caractères.

En effet comment ne pas s'effrayer d'un héros qui tue ses semblables? Or le propre de la litterature populaire repose, nous l'avons vu, sur son caractère rassurant et amusant tout à la fois. La différence des classes qui délimitait par le passé la frontière des rôles entre voleur et vole, trompeur et trompé, agresseur et victime, constituait la meilleure assurance pour le pauvre qui pouvait rire sans crainte. L'identification devient plus problématique à mesure que se rapprochent le meurtrier et la victime. Le nivellement da à l'atténuation des différences sociales et idéologiques de tous ordres entraîne la confusion des rôles. La masse des lecteurs ou des téléspectateurs doit pouvoir se situer unanimement et sans ambiguilté dans le même clan pour éprouver le plaisir recherché. C'est ainsi que la science fiction entre en jeu, créant des différences fondamentales entre les êtres, creusant de nouveaux fossés entre les intérêts et inventant des monstres sur le compte desquels il est impossible de se tromper. Le procédé n'est pas nouveau. On lui doit déjà les dragons, les licomes, les blemmyes, les monopodes, etc., qui peuplèrent les récits de voyage des explorateurs et qui s'évanouirent à mesure que les régions qu'ils habitaient étaient mieux connues.

Cet examen très rapide d'un type populaire de criminel fictif débouche sur une question plus générale : comment expli- 
quer que les manifestations de la culture populaire orales, écrites ou télévisuelles se soient toujours intéressées au crime? A cause de son ambivalence d'interprétation, il a sans doute constitué une sorte de trame constante, de sujet privilégié autour duquel se sont cristallisés contes, chansons, pièces de théâtre, romans et films. Pour la même raison, les tabous ont été contournés beaucoup plus facilement que pour d'autres interdits comme le sexe, par exemple. Rappelons que le crime a toujours été lié à une dialectique de libération et de contrainte. La sagesse et la crainte populaire ont toujours exercé sur les histoires de crime une censure prudente. C'est pourquoi un sujet destiné à fournir plaisir et sécurité ne pouvait que se maintenir à l'arrière-garde de la chose littéraire. Il en va tout autrement de la littérature tout court qui à partir du XIX siècle a rompu les entraves religieuses pour accorder pleine autorité aux exigences du \& moi », 4 ici \$, maintenant \$. Depuis lors, on assista au déferlement torrentiel de toutes les démences des plus bénignes aux plus géniales. Mais c'est un autre problème.

\section{BIBLIOGRAPHIE}

BELL, P. (1979) : les Contradictions culturelles du capitalime, Paris, Presses Universitaires de France.

BENICHON, P. (1948) : Morales du grand siecle, Paris, Editions du Seuil.

BIGSBY, C.W.E. (1975) : Superculture. American Popular Culture and Europe, London, Paul Elek.

ELIADE, M. (1976) : Histoire des croyances et des idées religieuses, Paris, Payot.

FOUCAULT, M. (1975) : Surveiller et punir, Paris, Gallimard.

MALINOWSKI, B. (1968) : Une théorie scientifique de la culture, Paris, F. Maspero.

NARCEJAC, T. (1967) : \& Le roman policier `, Histoire des littératures, tome III, sous la direction de R. Queneau, Encyclopédie de la Pléiade, Paris, Gallimard.

WHITMAN, W. (1933) : Walt Whitman - Ses meilleures pages, traduit de l'anglais par R. Dion-Laberge, Montréal, Les Elzévirs. 